\title{
Students and teachers' perception of an effective clinical nurse teacher characteristics: A comparative study
}

Andres Siron Panlican, Salman Al Saqri, Sage Raguindin, Liza M. Villacorte, Petelyne Pangket

Medical Surgical Department, College of Nursing, University of Hail, Saudi Arabia

Received: June 29, 2020

DOI: $10.5430 /$ jnep.v10n $11 \mathrm{p} 48$
Accepted: July 16, 2020

Online Published: July 24, 2020

URL: https://doi.org/10.5430/jnep.v10n11p48

\begin{abstract}
Objective: This study aims to determine the level of perception of nursing students and teachers on the effective clinical nurse teacher characteristics and find if there is a significant difference between the level of perception of nursing students and teachers according to their demographic features.

Methods: This study employed a descriptive - comparative design. Simple random sampling was undertaken and a questionnaire developed by Brown (1981) was utilized in gathering information from the participating 244 nursing students and 46 teachers as respondents. Frequency, percentage, $t$-test, F-test in Statistical Package for the Social Sciences (SPSS) version 22 was used in the analysis of data.

Results: Most of the participating nursing students in the study are aged 18-22-year-old, female, and unmarried while most teachers were more than 46-year-old, female, and married. Among the three indicators of effective clinical teacher characteristics, the teachers consider professional competence, relationships with the students' most important, and personal attributes as very important while the nursing students perceived all as very important. A significant difference exists in the level of perception of both groups of respondents on different indicators. However, in certain demographic profile, specifically gender and marital status there seem to be no significant difference but it exists with age.

Conclusions: Both nursing students and nurse-teachers perceived that an effective clinical teacher characteristic has a significant influence on the clinical learning course of students. The perception varies significantly with age and this would suggest that as the nurse grows older and gain more experience his/her perceptions matures.
\end{abstract}

Key Words: Nurse educator, Efficient, Clinical teacher, Qualities

\section{INTRODUCTION}

Clinical exposures or learning experiences in various clinical settings catering to patient care are essential in molding nursing students with the knowledge, skills, and attitude leading them to become proficient professional nurses in the future. ${ }^{[1,2]}$ However, studies show that clinical experience is not only vital in providing fundamental nursing compe- tencies to students ${ }^{[3]}$ but most importantly it develops their clinical judgment, critical thinking, interpersonal skills, and communication. $^{[4,5]}$ Likewise, the clinical learning experience should provide opportunity for students to practice teamwork, cooperation and interprofessional collaboration with the nurse teacher and other health care professionals. ${ }^{[6]}$ The quality of clinical learning by nursing students during

${ }^{*}$ Correspondence: Andres Siron Panlican; Email: andy_panlican@yahoo.com; Address: Medical Surgical Department, College of Nursing, University of Hail, Saudi Arabia. 
such clinical exposure depends on their characteristics, professional attitude, values, knowledge, and skills. ${ }^{[7,8]}$ Emerging evidence suggests that meaningful clinical experience is difficult to be achieved by the nursing students with their attributes without the influence of the characteristics of clinical nurse teacher. Clinical nurse educators play a pivotal role in the student's learning process and their interaction alone can either ease or impede the student's learning and self-efficacy in the clinical area. ${ }^{[9,10]}$ However, a lot of students viewed their clinical nurse teachers as evaluators and limits the trust in order to vent out their concerns. ${ }^{[11]}$ Salem et al. (2019) also noted that clinical nurse teacher characteristics may have a direct positive or negative impact in facilitating the transfer of theory into practice during classroom instruction or clinical learning environment. ${ }^{[12]}$

The characteristics, attributes, and teaching behaviors of nurse instructors are a common subject of various studies in the past decades. ${ }^{[5]}$ The twenty-nine related articles integrative reviewed by Labrague et al. (2019) indicated that the personal attributes of the nursing faculty are the meanest being valued by nursing students. A research study in Australia and other countries revealed that the most appreciated characteristic of a clinical educator is interpersonal relationships. ${ }^{[13,14]}$ Meanwhile, nursing students and nurse educators at the University of Gondar, Northwest Etiopia, perceived that the most indispensable characteristics of a nurse educator are nursing competencies. ${ }^{[15]}$ From the said studies, it can be observed that the characteristics being appreciated by the nursing students and nurse educators differ in many cases. Taking into account the students' viewpoints on which among these were effective, to promote learning, can be the best way to achieve it. Clinical nurse faculty should learn how to meet the needs of nursing students with varying learning capabilities and sociocultural backgrounds. ${ }^{[16]}$

This parallel study is conceptualized to compare if the clinical nurse teacher and nursing students have a significant difference in their perception of the characteristics of an effective clinical nurse teacher specifically on professional competence, relationship with the students, and personal attributes indicator across their demographic features. Also, the authors of this study hypothesized that nursing students and teachers have high-level perceptions of the characteristics of clinical nurse teachers.

Relevant nursing education in every country is critical in producing competent nurses but to realize this, the characteristics of an effective clinical nurse educator must have to be considered. ${ }^{[17,18]}$ There were numerous studies conducted in the characteristics of nurse educator but it appears to be none in the Kingdom of Saudi Arabia (KSA) as of 2019. Thus, studying what are the perceptions of the students and teachers in the effective clinical nurse teacher characteristics is highly imperative since the quality of nursing education in the KSA especially that its BSN program which was officially started in 2004 is still considered new.

\section{METHODS}

\subsection{Research design}

This study utilized descriptive comparative design in determining the perception of student and teacher on the effective clinical teacher characteristics and its significant difference in the responses of respondents and their demographic aspects. The participants are limited only to nursing students from level 5 to 8 while only those faculty members who are engaged in both lectures and hospital-based instructions served as respondents.

\subsection{Population and sampling}

The study was conducted at the University of Ha'il (UOH) during the first semester of the academic year 2019-2020. Data collection was done and completed on the later part of the semester ensuring that the students have sufficient period of related learning experiences with their clinical nurse teacher in the major hospitals and primary health care centers in the City of Hail. UOH is a public higher education institution in Hail City located in the north-western part of Saudi Arabia. It offers regular and bridging nursing programs. There were 44 nurse teachers and 244 nursing students enrolled in level 5 to 8 in the 2019-2020 academic year who participated in the study.

Nursing students from levels 1 to 4 were excluded in this study due to lack of exposures with nursing instructors who are involved not only in the classroom instructions or simulations in the laboratory but also in a hospital or clinic-based practices. In the same way, nursing faculties who were involved or performed only in lecture-based classes were also excluded.

\subsection{Data gathering procedure}

Upon approval of the proposal to conduct this research by the Dean of the College of Nursing, the authors immediately convened an orientation and data gathering activity with the target respondents. The details of the study were presented with emphasis on the purpose, the significance of the study, and the rights to either volunteer or decline to participate. Questionnaires as a research tool were distributed to those willingly participated and at least 20 minutes of spare time was provided for the respondents to answer the questions. 


\subsection{Instrument}

A structured questionnaire, the Clinical Teacher Characteristics Instrument (CTCI) developed by Brown (1981) was employed as a tool in gathering primary data. ${ }^{[19]}$ The tool consists of 3 parts, the first of which is the general instructions on how to answer the questions, the second part encompasses the demographic factors of respondents, and third is the CTCI questions that cover 20 items on the Professional Competence (PC), Relationship with Students (RS), and Personal Attributes (PA) of the clinical nurse teacher. These characteristics used a 5 points Likert- scale: (5) most important, (4) very important, (3) important, (2) less important, (1) not important. As a disclaimer, there was no authorization requested from the developer to make use of the tool however, the authors allowed researchers to use it provided that proper citation is executed.

\subsection{Ethical considerations}

This study obtained ethical approval from the ethical review board of the University of Ha'il. Before the conduct of data gathering, the objective of the research was explained to the students and teachers. Those who signed the consent and voluntarily agreed to participate were ones given a questionnaire. After the collation and recording of data, the data filled questionnaires were kept confidential and stored in a safe place to protect the profiles and responses of respondents from being disclosed.

\subsection{Data analysis}

The data collected were treated with the Statistical Package for the Social Sciences (SPSS v21). Descriptive statistics such as frequency and percentages were used for the demographic profile; mean scores and Standard Deviations (SD) for the perceptions of respondents on the effective clinical nurse teacher characteristics; and independent t-tests/F-test for the determination of significant difference of respondent's perceptions on the effective characteristics of clinical nurse teacher and their demographic profile.

\section{RESUlts}

Table 1 shows the frequency and percentage distribution of student and teacher demographic profiles according to age group, gender, and marital status. Almost all or $222(91.0 \%)$ out of the 244 student respondents belong to 18-25-year-old age bracket and 142 are females $(58.2 \%)$ dominating the 102 males $(41.8 \%)$ student respondents. By marital status, 214 $(87.7 \%)$ of the student respondents are unmarried. On the other hand, most of the teacher respondents with a frequency of $21(45.6 \%)$ belong to the 46-year-old or more age group. It is also apparent that female teachers are more in number with a frequency of $29(63.0 \%)$ compared to only 17 male teachers $(37.0 \%)$. The majority of the teachers who took part in the study are married with a corresponding frequency of 37 or an equivalent of $80.4 \%$.

Table 1. Teachers and students demographic profile

\begin{tabular}{|c|c|c|c|c|c|}
\hline \multirow{2}{*}{\multicolumn{2}{|c|}{ Demographic Profile }} & \multicolumn{2}{|l|}{ STUDENT } & \multicolumn{2}{|l|}{ TEACHER } \\
\hline & & Frequency & Percentage (\%) & Frequency & Percentage (\%) \\
\hline \multirow{5}{*}{ Age Group } & 18-25-year-old & 222 & 91.0 & - & - \\
\hline & 26-32-year-old & 11 & 4.5 & 8 & 17.4 \\
\hline & 33-39-year-old & 7 & 2.9 & 8 & 17.4 \\
\hline & 40-46-year-old & 4 & 1.6 & 9 & 19.6 \\
\hline & > 46-year-old & - & - & 21 & 45.6 \\
\hline \multirow{2}{*}{ Gender } & Female & 142 & 58.2 & 29 & 63.0 \\
\hline & Male & 102 & 41.8 & 17 & 37.0 \\
\hline \multirow{2}{*}{ Marital Status } & Married & 30 & 12.3 & 37 & 80.4 \\
\hline & Unmarried & 214 & 87.7 & 9 & 19.6 \\
\hline
\end{tabular}

Table 2 displays the differences in the characteristics of an effective clinical teacher as perceived by students and faculty. Based from the result, students perceived that all of the indicators are very important characteristics of a clinical teacher, however their relationship with their teacher has the highest mean score of 3.64 (SD of 1.00) followed by personal attributes with a mean score of 3.58 (SD of .986) and professional competence with a mean score of 3.57 (SD of .995). On the other hand, teachers perceived that profes- sional competence and relationship with the students as most important having a mean score of 4.56 (SD of .617) and 4.54 (SD of .599) but then personal attributes are regarded by the teacher as very important having a mean score of 4.38 (SD .686).

Table 3 illustrates the significant difference in the perception of students and teachers on the effective clinical nurse teacher characteristics. As per paired sample $t$-test results on the perception of respondents across the three indicators, 
the $t$-value of each indicator such as the professional competence is 6.475 , relationship with students is 5.830, and a personal attribute is 5.253 and that the $p$-value of these indicators is lesser than .001 and .05 . This suggests that there is a significant difference between the perceptions of the teacher and students on the effective clinical nurse teacher characteristics.

Table 2. Effective Clinical Nurse Teacher Characteristics as Perceived by themselves and their Students

\begin{tabular}{llllll}
\hline \multirow{2}{*}{ Indicators } & \multicolumn{2}{l}{ Student } & & \multicolumn{2}{c}{ Faculty } \\
\cline { 2 - 3 } \cline { 5 - 6 } & Mean & SD & & Mean & SD \\
\hline Professional competence & 3.57 & .995 & & 4.56 & .617 \\
Relationship with students & 3.64 & 1.00 & & 4.54 & .599 \\
Personal attributes & 3.58 & .986 & & 4.38 & .686 \\
\hline Note. 4.50-5.00 = most important, 3.50-4.49= very important, 2.50-3.49= \\
important, 1.50-2.49=less important, 1.00-1.49 = not important
\end{tabular}

Table 4 displays the differences in the perception of teachers and students on the effective clinical teacher characteristics according to their demographic profile. It shows that the perceptions of students along with their age group have $p$-values (PC is .011, RS is .013, and PA is .010) lesser than .05 and far lower compared to that of their teacher's response which has $p$-values ( $\mathrm{PC}$ is .778, $\mathrm{RS}$ is .641, $\mathrm{PA}$ is .347) higher than .05. This implies that there is a significant difference in the response of the students along with age.

Table 3. Differences in the Effective Clinical Nurse Teacher Characteristics as Perceived by themselves and their Students

\begin{tabular}{lllll}
\hline Indicators & $\boldsymbol{t}$ & df & $\begin{array}{l}\text { Sig. } \\
\text { (2-tailed) }\end{array}$ & Remarks \\
\hline Professional competence & 6.475 & 288 & .001 & Significant \\
Relationship with students & 5.830 & 288 & .001 & Significant \\
Personal attributes & 5.253 & 288 & .001 & Significant \\
\hline
\end{tabular}

Table 4. Comparison in the Perception of Teacher and students on the Effective Clinical Teacher Characteristics according to their Demographic Profile

\begin{tabular}{|c|c|c|c|c|c|c|}
\hline \multirow{2}{*}{ Demographic Profile } & \multicolumn{3}{|c|}{ STUDENT (p-value) } & \multicolumn{3}{|c|}{ FACULTY (p-value) } \\
\hline & PC & RS & PA & PC & RS & PA \\
\hline Age Group & $\begin{array}{l}.011^{*} \\
(\mathrm{f}=3.76)\end{array}$ & $\begin{array}{l}.013^{*} \\
(\mathrm{f}=3.66)\end{array}$ & $\begin{array}{l}.010^{*} \\
(\mathrm{f}=3.85)\end{array}$ & .778 & .641 & .347 \\
\hline Gender & 0.331 & 0.115 & 0.259 & .616 & .502 & .512 \\
\hline Marital Status & .054 & .112 & $\begin{array}{l}.028^{*} \\
(t=2.20)\end{array}$ & .760 & .672 & .934 \\
\hline
\end{tabular}

*Significant Difference $(p$-value $\leq .05)$

It can also be observed that the resulting p-values of both the teacher and students are higher than 0.05 under gender and marital status although much higher on the part of the teachers. It means that gender and marital status do not lead to a significant difference in the respondent's perception except on the personal attributes which have contradicting $p$-values of .028 and .934 for the students and teachers respectively. The $p$-value at .054 of professional competence under the students almost opposes that of the teachers at far .760. Such opposing p-values indicate a statistically significant difference.

\section{Discussion}

The core purpose of a descriptive-comparative study is to determine differences if any in the perceptions of students and teachers on the effective characteristics of clinical nurse teacher and their demographic features. In this study, the students who participated are a largely young adult, single, and female while most of the participating teachers belong to the middle age group, married, and the majority are female.

Published by Sciedu Press
Students perceived that personal attributes, relationship with the student, and professional competence of a clinical nurse teacher are crucial elements in refining their nursing competencies in the clinical area. The clinical nurse teachers on the other hand perceived that characteristics of an effective clinical nurse teacher are all necessary and should be possessed by them. The above result confirms the study of Banan \& Elsharkawy (2017) at Cairo University finding that interpersonal relationships as a characteristic of a clinical teacher were most appreciated both by the nursing students and clinical instructors. ${ }^{[20]}$ However, professional competence and personal traits are least appreciated. Clinical teachers in these studies should have consistent awareness of their professional responsibilities since it has a boundless influence on the clinical learning processes for nursing students. It is in this context that teachers should capacitate themselves to respond to the diverse educational needs of the learners. ${ }^{[21]}$ This finding contributes to the understanding of the Universities or academic institutions in capacitating nurse-teachers on the characteristics of effective clinical nurse teachers. 
The findings of Soriano and Aquino (2017) in their study on the characteristics of a good clinical teacher in one university in the Philippines, teachers perceived that their teaching skills and nursing competence are the most imperative features while, students professed that personal trait and interpersonal relationship with their teacher is the utmost significant effective characteristics of a clinical teacher. ${ }^{[22]}$ Okoronkwo, et al. (2013) discussed in their study on exploring the perceptions of students on the qualities of a clinical teacher and it showed that the behavior of a teacher in the clinical setting has the highest rating. ${ }^{[23]}$ At the level of the teacher, it is expected that they define the qualities of a professional teacher in the clinical area while the students who are still on the process of developing their clinical skills, they are expected to have their particular favored characteristics of a clinical teacher. Indeed, such expectation can be used to help the clinical instructor in meeting the diverse needs of the learners especially on the styles that meets their preferred learning. ${ }^{[24]}$

In addition, on the part of the students, interpersonal relationship on how the teacher deal with their students matters most. Students feel less anxious in their clinical exposure when they know that their teacher is always available to assist them when a situation arises and when the teacher is encouraging, inviting, and shows respect. It is also important that the clinical faculty demonstrates the ability to stimulate students to learn. These interpersonal skills are the helpful aspect to facilitate student's learning in the clinical settings. ${ }^{[25-28]}$ Contrary to the views of the students, clinical nurse teachers perceived that it is more important to possess the characteristics that deal with professional competence than their relationship with the students. In 2019, an integrative review of articles that focused on effective teaching behaviors of nursing teachers showed that "professional competence" is the most desirable characteristics for nursing faculty. ${ }^{[5]}$ It is viewed that to be effective in the clinical area, the teacher must be a role model or one who can demonstrate skills, attitude, and values that can be developed by the students, knowledgeable on teaching strategies to stimulate students to learn and know how to be fair and objective in giving

\section{REFERENCES}

[1] Shin KR. The Meaning of the Clinical Learning Experience of Korean Nursing Students. Journal of Nursing Education. 2000; 39(6): 259265. https://doi .org/10.3928/0148-4834-20000901-06

[2] Rajeswaran L. Clinical Experiences of Nursing Students at a Selected Institute of Health Sciences in Botswana. Health Science Journal. 2017; 10(6). https ://doi.org/10.21767/1791-809X.100047 1 evaluation to students. However, an opposing result was seen in old and recent studies. The research done by Mogan and Knox (1985) was one of the pioneer studies on the subject matter. ${ }^{[29]}$ It reported that faculty focused on the nursing competence while the replication study in Australia linked faculty on interpersonal relationships.

Another possible reason for the variation in the views of the respondents is their age differences. Maturity is a key factor in the way they perceived the important aspects a student need from their teacher. Nursing student's age can be a factor to facilitate understanding of their roles in the clinical setting ${ }^{[30]}$ whereas teachers can effortlessly facilitate their learning. Mature individuals view that teachers must possess skills and competencies of a nurse that can be acquired by students to be considered effective. ${ }^{[13]}$ It is evident with the other findings of the study where marital status affects the way the students determine the desirable characteristics of a clinical instructor, wherein most of the married students correspond with the older students that give higher ratings specifically on the personal attributes aspect. The results show that older students who belong to the bridging program had similar views as their teachers. Some studies conducted on a similar concept compared the perception based on the level of student. ${ }^{[26,31,32]}$ However, despite the difference that existed in their findings, none of them attribute the variation with age.

\section{Conclusion}

In this study, the teacher perceived that personal attributes, relationships with the student, and professional competence are the most important characteristics that a teacher must possess while the students perceived it as a very important element of an effective teacher. The differences in the level of perception of $n$ the effective clinical nurse teacher characteristics are greatly influenced by age and some degree by marital status. It can be said that as the nurse grows older and gain more experience his/her perceptions matures.

\section{CONFlicts OF INTEREST Disclosure}

The authors declare that there is no conflict of interest.
[3] O'Rae A, Langille J, Li A, et al. The Evolving Role of a Clinical Instructor in an Integrated Undergraduate Nursing Curriculum. Journal of Nursing Education and Practice. 2017; 7(4): 87-95. https://doi.org/10.5430/jnep.v7n4p87

[4] Jansson I, Ene KW. Nursing students' evaluation of quality indicators during learning in clinical practice. Nurse Education in Practice. 2016; 20: 17-22. PMid:27428799 https://doi.org/10.1016/j . nepr.2016.06.002 
[5] Labrague L, McEnroe-Petitte DM, D'Souza MS, et al. Nursing Faculty Teaching Characteristics as Perceived by Nursing Students: An Integrative Review. Scandinavian Journal of Caring Science. 2019; 34(1): 23-33. PMid:31062401 https://doi.org/10.1111/scs . 12711

[6] Palese A, Gonella S, Brugnolli A, et al. Nursing Students' Interprofessional Educational Experiences. BMJ Open. 2019; 9: e025575. PMid:30898820 https://doi .org/10.1136/bmjopen-2018-0 25575

[7] Fukada M. Nursing Competency: Definition, Structure, and Development. Yonago Acta Medica. 2018; 61(1): 1-7. PMid:29599616 https://doi.org/10.33160/yam.2018.03.001

[8] Reljić NM, Lorber M, Vrbnjak D, et al. Assessment of Clinical Nursing Competencies: Literature Review. Teaching and Learning in Nursing. 2017; 5: 49-67. https://doi .org/10.5772/67362

[9] Rowbotham M, Owen RM. The Effect of Clinical Nursing Instructors on Student Self-efficacy. Nurse Education in Practice. 2015; 15(6): 561-566. PMid:26482402 https://doi.org/10.1016/j . nepr.2015.09.008

[10] Madhavanprabhakaran GK, Shukri RK, Hayudini J, et al. Undergraduate Nursing Students' Perception of Effective Clinical Instructor: Oman. International Journal of Nursing Science. 2013; 3(2): 38-44. https://doi.org/10.5923/j.nursing. 20130302.02

[11] Palese A, Gonella S, Destrebecq A. Manusutti I., Morsanutto, M.,... Dimonte, V. (2018). Opportunity to Discuss Ethical Issues during Clinical Learning Experience. SAGE Nursing Ethics. 2018; 1-15. PMid:29783904 https://doi.org/10.1177/09697330187746 17

[12] Salem OA, Abdulrhman N, Muhawish H. Nursing Students' Perceptions of Clinical Teaching Behaviors. American Journal of Biomedical Science \& Research. 2019; 5(2). https ://doi .org/10.34297 /AJBSR. 2019.05.000895

[13] Lee WC, Cholowski K, Williams AK. Nursing students' and clinical educators' perceptions of characteristics of effective clinical educators in an Australian university school of nursing. Journal of Advanced Nursing. 2002; 39: 412-20. PMid:12175350 https: //doi.org/10.1046/j.1365-2648.2002.02306.x

[14] Collier AD. Characteristics of an Effective Nursing Clinical Instructor: The State of the Science. Journal of Clinical Nursing. 2017. PMid:28618100 https://doi.org/10.1111/jocn. 13931

[15] Bifftu BB, Berihun AD, Bewket TT, et al. Effective Clinical Teaching Behaviors Views of Nursing Students and Nurse Educators at the University of Gondar, Northwest Ethiopia: Cross-Sectional Institution Based Study. Journal of Caring Science. 2018; 7(3): 119-123. PMid:30283755 https://doi.org/10.15171/jcs.2018.019

[16] Mikkonen K, Elo S, Tuomikoski AM, et al. Mentor Experiences of International Healthcare Students' Learning in a Clinical Environment: A systematic review. Nurse Education Today. 2016; 40: 87-94. PMid:27125155 https://doi.org/10.1016/j.nedt. 2016.02 .013

[17] Fawaz MA, Hamdan-Mansour AM, Tassi A. Challenges Facing Nursing Education in the Advanced Healthcare Environment. International Journal of Africa in Nursing Sciences.2018; 9: 105-110. https://doi.org/10.1016/j.ijans.2018.10.005

[18] Kermansaravi F, Navidian A, Yaghoubinia F. Nursing Students' Views of Nursing Education Quality: A Qualitative Study. Global Journal of Health Science. 2015; 7(2): 351-359. PMid:25716411 https://doi.org10.5539/gjhs.v7n2p351
[19] Brown ST. Faculty and Student Perceptions of Effective Clinical Teachers. Journal of Nursing Education. 1981; 20(9): 4-15. PMid:6273375 https://doi .org/10.3928/0148-4834-19811 101-03

[20] Banan S, Elsharkawy N. Undergraduate Nursing Students' and Clinical Instructors' Perceptions of the Characteristics of an Effective Clinical Instructor at the Faculty of Nursing, Cairo University. American Journal of Nursing Science. 2017; 6(3): 185-192. https://doi.org/10.11648/j.ajns. 20170603.16

[21] Pasay-an E, Pangket P, Nialla J, et al. Work Life Balance among Nurse Educators towards Quality Life: A Mixed Method Study. International Journal of Sciences: Basic and Applied Research. 2014; 18(1): 386-401.

[22] Soriano G, Aquino M. Characteristics of a Good Clinical Teacher as Perceived by Nursing Students. International Journal of Nursing Science. 2017; 7(4): 96-101. https://doi.org/10.5923/j.nu rsing20170704.04

[23] Okoronkwo J, et al. Students' Perception of Effective Clinical Teaching and Teacher Behaviour. Open Journal of Nursing. 2013; 03(01): 63-70. https//doi.org/10.4236/ojn.2013.31008

[24] Alshammari MH, Pacheco H, Alboliteeh M, et al. Faculty Teaching Styles and the Learning Preference among Nursing Students: A selfreported study. University of Ha'il-Journal of Science. 2019; 1(1): 19-27.

[25] Koy V. Perceptions of Nursing Students on Effective Clinical Preceptors in Phnom Penh National Hospitals, Cambodia. International Journal of Research in Medical Science. 2015; 3: 1605-10. https://doi.org/10.18203/2320-6012.ijrms20150237

[26] Lovrić R, Prlić N, Barać I, et al. Specificities and Differences in Nursing Students' Perceptions of Nursing Clinical Faculties' Competences. Journal of Professional Nursing. 2014; 30(5): 406-417. PMid:25223289 https://doi.org/10.1016/j.profnurs. 201 4.03 .005

[27] Niederriter JE, Eyth D, Thoman J. Nursing Students' Perceptions of the Characteristics of an Effective Clinical Instructor. SAGE Open Nursing. 2017; 3: 1-8. https ://doi .org/10.1177/2377960816 685571

[28] Valiee S, Moridi G, Khaledi S, et al. Nursing Students' Perspectives on Clinical Instructors' Effective Teaching Strategies: a descriptive study. Nurse Education in Practice. 2016; 16(1): 258-262. PMid:26489603 https://doi.org/10.1016/j.nepr.2015.09 .009

[29] Mogan J, Knox J. Important Clinical Teacher Behaviours as Perceived by University Nursing Students, Students, and Graduates. Journal of Advanced Nursing. 1985; 10: 25-30. PMid:3844410 https://doi.org/10.1111/j.1365-2648.1985.tb00488.x

[30] Alshammari F, Pangket P, Llego J, et al. Adaptation of Nurse Interns in Acute Hospital Care Practice and their Demographic Features: A Correlation Study. International Journal of Innovation, Creativity and Change. 2020; 12 (6): 323-333.

[31] Sabog RF, Caranto LC, David JJ. Effective Characteristics of a Clinical Instructor as Perceived by BSU Student Nurses. International Journal of Nursing Science. 2015; 5(1): 5-19. https: //doi.org/10.5923/j.nursing. 20150501.02

[32] Hewitt-Thompson K, Rae T, Anderson-Johnson PA. Descriptive, Cross-sectional Study Analyzing the Characteristics of an Effective Clinical Instructor: Perceptions of Baccalaureate Nursing Students. International Journal of Nursing. 2016; 3(2): 20-29. https : //doi.org/10.15640/ijn.v3n2a3 